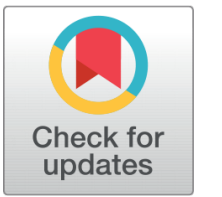

OPEN ACCESS

Received: 25-07-2020

Accepted: 25-08-2020

Published: 15-09-2020

Editor: Dr. Natarajan Gajendran

Citation: Tirpude S, Bharadwaj A, Sundaram R, Mane S, Holmukhe RM (2020) An investigation into awareness and usage of lead acid batteries in E-rickshaws: A field survey in New Delhi. Indian Journal of Science and Technology 13(33): 3467-3483. https://doi.org/ 10.17485/IJST/V13i33.1065

* Corresponding author.

Tel: +91-7559438072

saket_tirpude@yahoo.co.in

Funding: None

Competing Interests: None

Copyright: (c) 2020 Tirpude et al. This is an open access article distributed under the terms of the Creative Commons Attribution License, which permits unrestricted use, distribution, and reproduction in any medium, provided the original author and source are credited.

Published By Indian Society for Education and Environment (iSee)

ISSN

Print: 0974-6846

Electronic: 0974-5645

\section{An investigation into awareness and usage of lead acid batteries in E-rickshaws: A field survey in New Delhi}

\author{
Saket Tirpude ${ }^{1 *}$, Ankit Bharadwaj ${ }^{1}$, Rama Sundaram $^{2}$, Sidhartha Mane ${ }^{3}$, \\ Rajesh M Holmukhe 4
}

1 Student, Department of Electrical Engineering, Bharati Vidyapeeth (Deemed to be University) College of Engineering, Pune, 411043, Maharastra, India. Tel.: +91-7559438072 2 Vice President, Optixtal India Energy Solutions Pvt Ltd, Pune, 411043, Maharastra, India 3 Research Engineer, Optixtal India Energy Solutions Pvt Ltd, Pune, 411043, Maharastra, India 4 Associate Professor, Department of Electrical Engineering, Bharati Vidyapeeth (Deemed to be University) College of Engineering, Pune, 411043, Maharastra, India

\section{Abstract}

Objectives: The purpose of this study is to identify the reasons which contributed to the premature failure of the e-rickshaw battery that puts the e-rickshaw operator (ERO) in financial stress. Methods: A field survey was conducted from $1^{\text {st }}$ October 2019 to $30^{\text {th }}$ October 2019, in the North-West Delhi suburbs to extrapolate the shortcomings. Different EROs, charging station operators (CSOs), and battery vendors were interviewed with an administered questionnaire. The simple random sample consisted of 50 EROs, 20 CSOs, and 40 battery vendors. The quantitative data procured was scrutinized through descriptive as well as inferential analysis. Findings: Constant Current (CC) based chargers were found to be the major reason for the shortened life of the battery. These chargers along with other erroneous practices are preventing both the ERO and the CSO to get the full profitability that they could. It was found during the field survey that the e-rickshaw ecosystem is in a dire need of a fast-charging algorithm. This study investigates the technical concepts which are absent in the e-rickshaw technology like modern fast charging techniques such as Constant Current-Constant Voltage (CC-CV), PulseCurrent, Superimposed Pulse Frequency, Intermittent- Current Charing, and Interrupted Charge-Control Techniques (ICCT) and the Hybrid Energy Systems. Novelty/Benefit: The study succinctly points to the technological dots that remain unconnected in the e-rickshaw and shows how the CC-CV based fast charging algorithm and the hybrid energy systems could fill those technological gaps, increase the efficiency and profitability of the e-rickshaw ecosystem.

Keywords: E-rickshaw battery life; battery chargers; charging techniques; pulse current; superimposed pulse frequency; interrupted charge-control 


\section{Introduction}

India's transport demand has had an 8-fold increase since 1980 compared to any other Asian economy ${ }^{(1)}$. Road transport is a salient constituent in the Indian Transportation Sector accounting for a $5.4 \%$ share in the Indian GDP ${ }^{(2)}$. Road transport carries $90 \%$ of the country's passenger traffic and $65 \%$ of the country's freight. It utilizes $78 \%$ of the energy share used for transport, while rail and air each utilize $11 \%$ of the energy share ${ }^{(3)}$.

Within the Road Transport sector, three-wheeled vehicles especially cycle rickshaws and autorickshaws have been a popular choice for last-mile connectivity. One three-wheeled vehicle recently added to the list is e-rickshaw. Looking at the meteoric growth in the population of e-rickshaws every year in both urban and suburban areas across India, it is evident that this mode is one of the most popular transport utilities.

The e-rickshaws are electric motors energized by valve-regulated lead-acid (VRLA) batteries or lithium-ion batteries. Approximately $98 \%$ of the e-rickshaws run on VRLA batteries due to lesser costs than the lithium-ion ones ${ }^{(4)}$.

Most of the cycle rickshaw operators are switching to e-rickshaws considering the better-earning prospect accompanied by a decline in the human effort and time. Not just the cycle rickshaw operators, but the urban migrant population in need of work finds e-rickshaw as a lucrative job opportunity.

However, the e-rickshaw technology is failing to live up to its' promise because the battery fails much before its expected life. The feedback from EROs suggests they are unhappy with the dismal performance of their vehicles particularly the battery. The EROs expected a rise in their incomes, in reality, their expectations of profit are not met. Most of the EROs have to get their batteries replaced within 6 months. The current charging techniques and the charger, in particular, are the root cause of the problem of low life. This is accompanied by the EROs negligence towards the battery, the ERO being an unskilled person, isn't aware of the maintenance of the battery which is the heart of the e-rickshaw. Also, the battery sellers compromise on the quality of battery for their greed. All these factors lead the battery to fail earlier than expected. This puts the ERO in a financial turmoil. Those in need of earning may not find the e-rickshaw as a lucrative earning opportunity.

The purpose of this study is to highlight the inefficient charging techniques, mal operations, and illegal practices that lead to the premature death of the battery. This study points to how the main problem statement can be resolved by using alternate charging algorithms and hybrid energy systems which in turn boosts the e-rickshaw ecosystem by reducing the charging time, improving the profitability of the ERO and CSO and increasing the vehicle battery life.

\section{Statistics}

It is necessary to examine two statistical data sets; e-rickshaw population and e-rickshaw battery market size.

\subsection{E-rickshaw population}

Today, the e-rickshaw market in India is larger than in China ${ }^{(5)}$. Due to rampant under-reporting of imports of BLDC electric motors the exact figures are hard to estimate. Another reason for this unpredictable population is the absence of clear policies underlying the registration of these vehicles. Initially, e-rickshaws didn't require any registration and the mode remained unregulated by any central law in India ${ }^{(6)}$. While in certain states like Tripura registrations were made mandatory in 2014, Delhi, on the other hand, did not have any regulations until $2017^{(6)}$.

In the year 2014, it was reported that the e-rickshaw population figure was 1.5 million. Reputed consultancies report an addition of near 15,000 e-rickshaws every month or under 2,00,000 e-rickshaws per annum ${ }^{(6)}$. Hence, it can be inferred that the cumulative fleet is close to 2.5 million as of 2019. A growth of $15 \%$ per annum in the vehicle population is expected which when applied even on a base of 2 million would suggest an increment of 0.3 million per annum or $25,000 /$ month $^{(7)}$.

Cycle rickshaw operators switching towards e-rickshaws to gain the monetary benefit associated with this mode and the urban migrant population in need of job getting into this profession are two other major drivers behind the meteoric growth in the e-rickshaw population. [ Table 1] shows the estimated daily earnings of a cycle rickshaw operator and an ERO.

Table 1. Comparison between the estimated earnings of an e-rickshaw and a cycle rickshaw operator

\begin{tabular}{lll}
\hline Parameter & E-rickshaw & Cycle Rickshaw \\
\hline Estimated Daily Earnings (Rs.) & $800-1000$ & $200-500$ \\
\hline
\end{tabular}

If such being the growth rate, it is soon a possibility that the e-rickshaws will reach a 10 million mark in the coming years [ Figure 1]. Also, considering the many advantages that e-rickshaws possess, the e-rickshaws might be considered as a possible alternative to auto rickshaws. [ Table 2] shows a comparison between an auto-rickshaw and an e-rickshaw. 


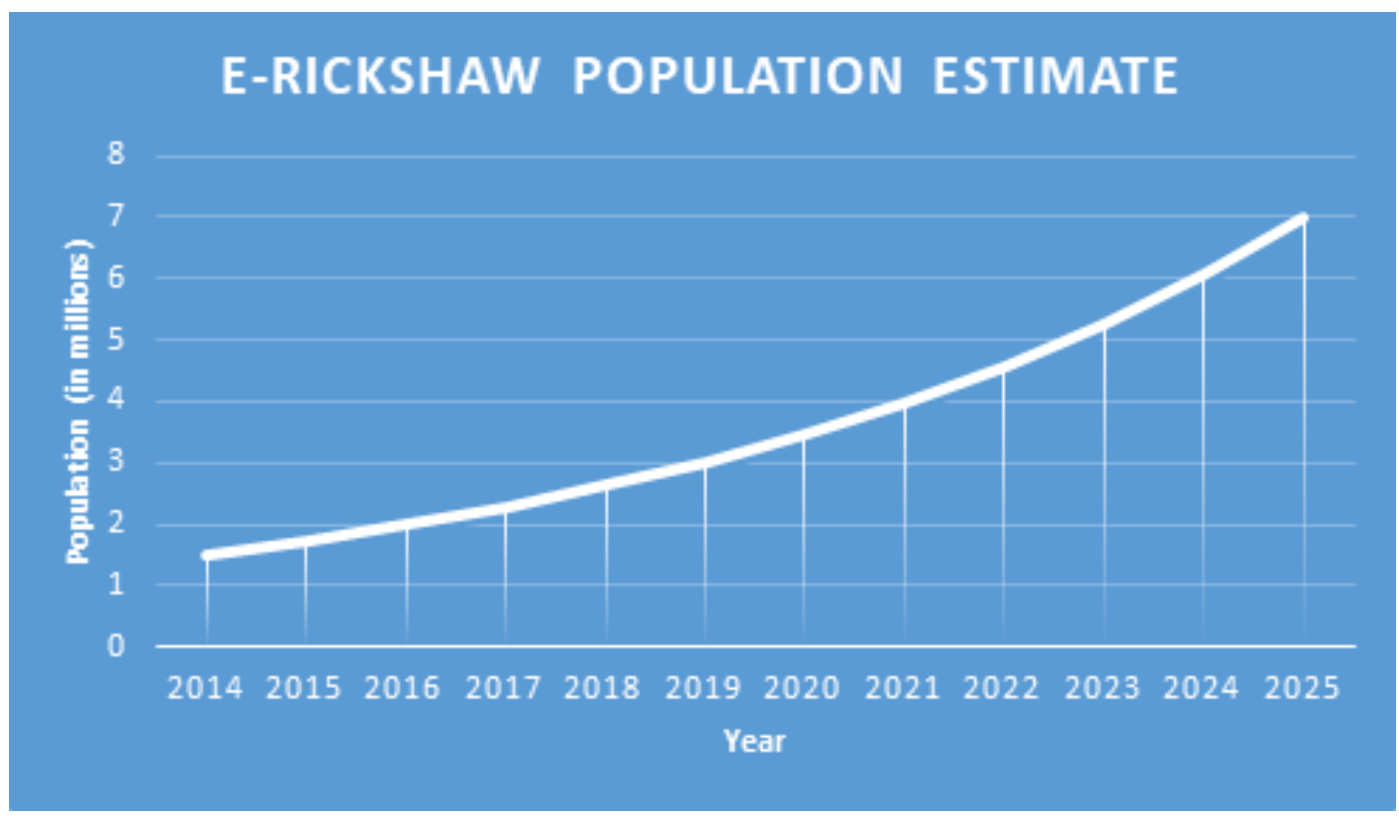

Fig 1. Forecast of e-rickshaw population up to 2025

Table 2. Comparison between autorickshaw and E-rickshaw

\begin{tabular}{|c|c|c|}
\hline Parameter & Autorickshaw & E-rickshaw \\
\hline Estimated Initial Price (Rs.) & $1,50,000 /-$ to $3,00,000 /-$ & $90,000 /-$ to $1,50,000 /-$ \\
\hline Passenger Ferrying Capacity & 3 & 4 \\
\hline Minimum Fare (Rs.) & $20 /-$ & $10 /-$ \\
\hline $\mathrm{CO}_{2}$ Emission $^{(1)}$ (Tailpipe) & $98 \mathrm{gm} / \mathrm{km}$ & Zero \\
\hline Specific $\mathrm{CO}_{2}$ Emission ${ }^{(2)}(\mathrm{gm} /$ passenger-km) & 22.556 & 19.129 \\
\hline Specific Energy Consumption ${ }^{(2)}(\mathrm{kJ} /$ passenger-km) & 362.4 & 53.76 \\
\hline Mileage & $43 \mathrm{~km} / \mathrm{kg}(\mathrm{CNG})$ & $80 \mathrm{~km} /$ charge \\
\hline
\end{tabular}

(1) Source: Reynolds, C., Kandlikar, M. and Badami, M., 2011. Determinants of PM and GHG emissions from natural gas-fueled auto-rickshaws in Delhi. Transportation Research Part D: Transport and Environment, 16(2), pp.160-165.

(2) Source: Majumdar, D. and Jash, T., 2015. Merits and Challenges of E-rickshaw as An Alternative form of Public Road Transport System: A Case Study in the State of West Bengal in India. Energy Procedia, 79, pp.307-314

\subsection{E-rickshaw battery market size}

The Indian e-rickshaw battery market is worth USD 385.0 million, with nearly 4.3 million units being sold in 2019 . The battery market is expected to increase with a CAGR of $13.2 \%$ for the forecast period (2020-2024). The revenue expected in the year 2024 is USD 722.3 million $^{(8)}$.

VRLA batteries are being used in the e-rickshaws since its inception. Technically, lithium-ion batteries are more apt and better suit the purpose. Although recently lithium-ion batteries are also being put to use still, mass adoption is impeded by the steep prices. In this study, the e-rickshaws running on lithium-ion batteries only made up for a $10 \%$ share while the e-rickshaws running on lead-acid batteries dominated with $90 \%$ share.

According to the standards specified by the International Centre for Automotive Technology (ICAT) and Automotive Research Association of India (ARAI), the standard energy pack should be $412 \mathrm{~V}$ batteries of $100 \mathrm{Ah}$. However, there are several e-rickshaws with $80 \mathrm{AH}$ battery capacity.

Major players in the e-rickshaw battery industry are Exide, Amaron, Okaya, Tata, Microtek, and Luminous. However, these brands make up only $26 \%$ of the sample in this study. Local battery manufacturers dominate the market with $74 \%$ share, offering lower prices and the same warranty period as that of branded batteries. Figure 2 shows why unbranded batteries are preferred there is a substantial price difference across all battery sizes, the overall price differential being $25.92 \%$. [Note: The overall price differential is an average of price differences across each Ah.] [Appendix A]. 


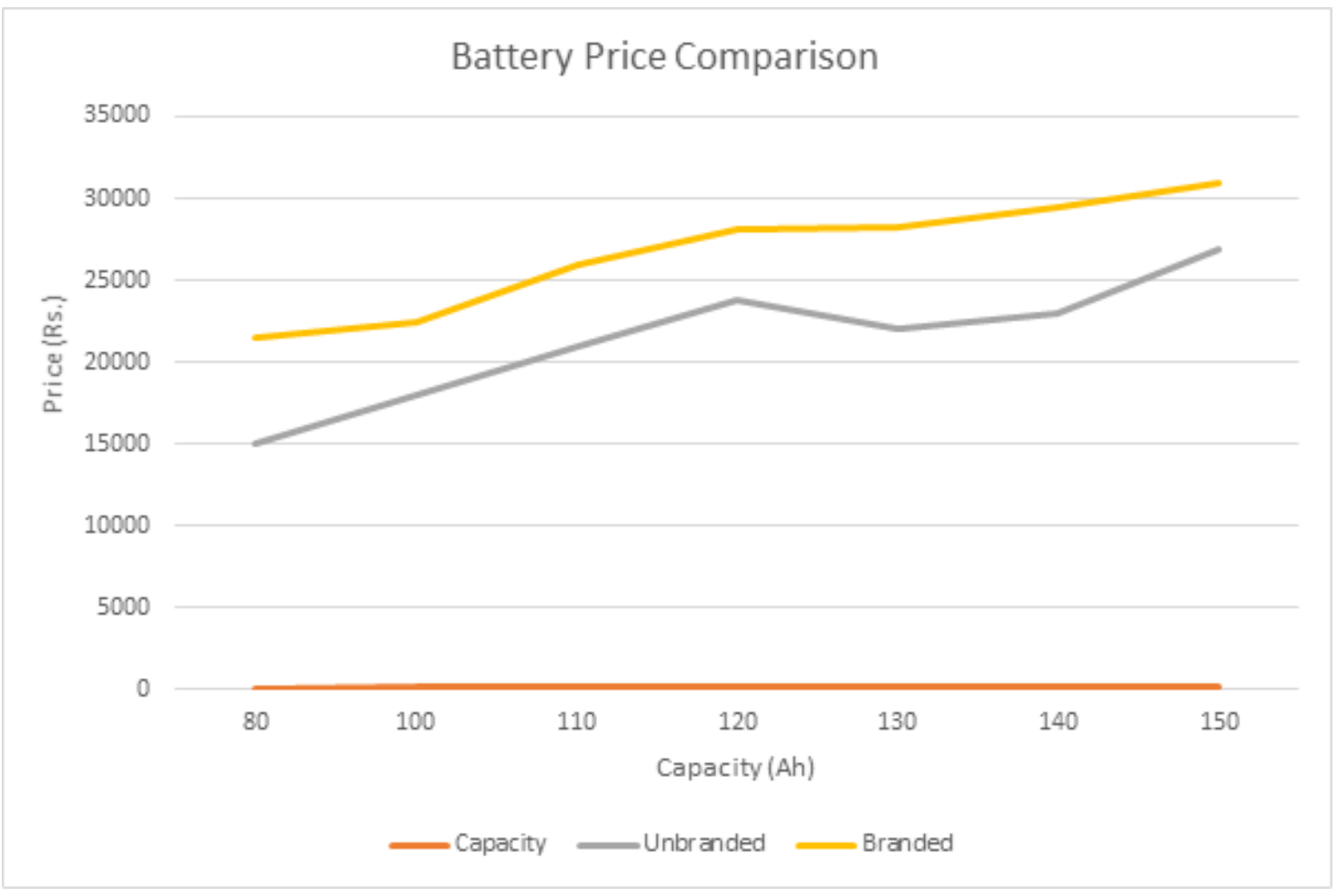

Fig 2. Price variation in branded and local batteries.

\section{Methodology}

This section is divided into two subparts; Data Collection Sources \& Procedures and Selection of Study Area.

\subsection{Data collection sources \& procedures}

In this study, the data was collected by conducting on-field survey. The information was gathered over 4 weeks starting from $1^{\text {st }}$ October 2019 to $30^{\text {th }}$ October 2019. The data regarding the practices carried out on field were obtained through one to one interviews with an administered questionnaire [Appendix B \& C]. The data collection procedure involved simple random sampling methodology for EROs, CSOs, and the battery vendors. The sample consisted of 50 EROs, where parameters such as battery type (Lead-Acid/Lithium-ion), charging location, ownership, and battery charging hours were obtained. The sample size for CSOs was 20 [Together which added up to 779 e-rickshaws], where the main parameters obtained were the e-rickshaw accommodating capacity, and the charging tariff (Rupees/Day). The study of the electricity bills at these CSOs was carried out to decipher the aberration. The questionnaires developed were unique to the ERO and the CSO. The gathered information mostly involved quantitative data which had both methods of the data analysis, i.e. descriptive analysis and inferential analysis. The descriptive statistical analysis was carried out for data through EROs and the CSOs. Inferential data analysis was carried out for predict the e-rickshaw population in the coming years and also to comprehend the reason for EROs preferring unbranded batteries over branded ones.

1. The energy consumption for various e-rickshaw was calculated by installing an energy meter at charging stations and noting the consumption.

2. The distance travelled by the e-rickshaw was confirmed by the odometers installed on the vehicles. The cost of energy consumption was extrapolated according to the electricity tariffs imposed in the state of Delhi (For reference, the electricity bill of one of the CSOs is enclosed in the Appendix D).

3. To obtain the prices of different VRLA batteries available for e-rickshaws, a market survey was conducted on both online as well as offline platforms to get a comparative glimpse of branded and unbranded VRLA batteries. 


\subsection{Selection of study area}

Prior to the main survey, a pilot survey was conducted to select the study area. For this, some relevant parameters had to be taken into account. These included the number of e-rickshaws in a given locality, the number of charging stations, the population of EROs, and proximity to nearby metro stations.

A pilot survey was conducted in areas such as Haiderpur, Shalimar Bagh, Jahangirpuri, Samaypur Badli, Rohini, Naharpur, Bawana where these parameters were scrutinized. Sufficing the parameters, Haiderpur village, Shalimar Bagh (North West Delhi) [Appendix E] was chosen due to the following reasons;

- Distance of the study area to nearby metro stations. Refer [ Table 3]

- Its connectivity to the Outer Ring Road, Azadpur vegetable market which gives EROs a major portion of their income during day time businesses.

- The large area of slums in the study area which is home to nearly 1,000 EROs.

- Within a radius of 5 kilometers, there were approximately 45 charging stations which would enable a large amount of field data to be gathered.

Table 3. Distance of the study area to nearby metro stations

\begin{tabular}{lll}
\hline Metro Station & $\begin{array}{l}\text { Proximity from Haiderpur, Shalimar Bagh } \\
\text { Sub Urban }\end{array}$ & ${ }^{\star}$ Number of e-rickshaws at the metro station \\
\hline Rohini Sector 18 & $2.7 \mathrm{Km}$ & 40 \\
Pitampura (Madhuban Chowk) & $3.5 \mathrm{Km}$ & 30 \\
Samaypur Badli & $4.3 \mathrm{Km}$ & 60 \\
Azadpur & $5.4 \mathrm{Km}$ & 35 \\
Rithala & $6.1 \mathrm{Km}$ & 60 \\
Rohini West & $5.0 \mathrm{Km}$ & 25 \\
Netaji Subhash Place & $5.6 \mathrm{Km}$ & 55 \\
\hline
\end{tabular}

\section{Concept of charging station}

The charging station is the equivalent of a petrol pump. The charging station provides the necessary electrical energy to recharge the battery of the e-rickshaw. $84 \%$ of the sample in this study, charged their e-rickshaws at these stations. $10 \%$ of the EROs who had the space to park the e-rickshaw at their home used power plugs to charge the e-rickshaw. $6 \%$ of the EROs, who had rented the e-rickshaw, charged at the owner's premises [Appendix F]. The primary reason for this is that most of the drivers come from nearby slums where they have no space to park their e-rickshaws. The charging station serves the purpose of providing energy to the vehicle, necessary parking space as well as relief from the security problems which the ERO has to encounter when the e-rickshaw is parked at his premises.

The Transport Department of NCT Delhi (Delhi Government) offers incentives for setting up charging stations and seeing this as a profitable opportunity, many entrepreneurs are getting into this business. The electricity tariffs for e-rickshaw charging stations are lesser when compared to the conventional tariffs imposed in the state. A separate energy meter is required to be installed at the premises. The fixed tariff for energy consumption in the state of Delhi is Rs $5.5 / \mathrm{kWh}$. The surcharges and rebates depend on the different time slabs as directed by the Tata Power Delhi Distribution Limited (TPDDL) which is the franchisee for North West Delhi.

Typically, the EROs come in the evening and leave their e-rickshaws to charge for overnight. The EROs have their chargers because the chargers are provided by the manufacturer at the time of purchase and are kept at the charging station. A guard is hired to look after the e-rickshaws and chargers, being trained to put the e-rickshaw to charge and remove it once the charging is over. The cost of charging for a day including the parking space in the study area is an average Rs 120/Day [Appendix G].

\section{Discussions}

The first week during the on-field survey was spent in building relationships with the CSOs and EROs. Different CSOs were interviewed and a sufficient amount of time was spent in their charging stations to know the situations on the ground level. As a result of the interactions with the ERO and CSO, many commonly held beliefs/practices came to light which are discussed below. 


\subsection{Battery chargers}

The battery chargers are sold as a package with the e-rickshaws. At the charging stations, a caretaker looks after each charger in the absence of the particular ERO. These chargers are conventional CC (Constant Current) based chargers which put in a constant current for vast intervals of time. These chargers have a transformer-based electrical circuit inside them and don't possess any type of monitoring system in them which could identify the current state of charge (SoC) in the battery. Also, in this modern era of power electronics, they lack the necessary features to regulate the power flow and cut the power supply when the battery gets charged. The constituents such as the transformer core of these chargers are imported from China and are just assembled in India. Based on the feedback by CSO, most of them turn faulty in weeks and need to be repaired many times. The CC based charging algorithm is a technically flawed system. The current is forced into the battery for long hours which surpasses the battery gassing voltage when put for a prolonged use. (Explanation: The voltage corresponding to which overheating of the electrolyte takes place causing hydrogen and oxygen gases to form is called gassing voltage.) It was found that the chargers are the primary reason for overcharging which in turn is responsible for other major problems.

The battery chargers being used in the study area have a basic electrical circuit comprising of heavy transformers which add up to the weight and lack stability. Also, these chargers fail to operate at their rated values and have an efficiency of 50$60 \%$ which results in unnecessary exorbitant prices in the electricity bills, paid by the CSO. [ Figure 3] shows a conventional transformer-based charger and [ Figure 4] shows its inner transformer assembly.

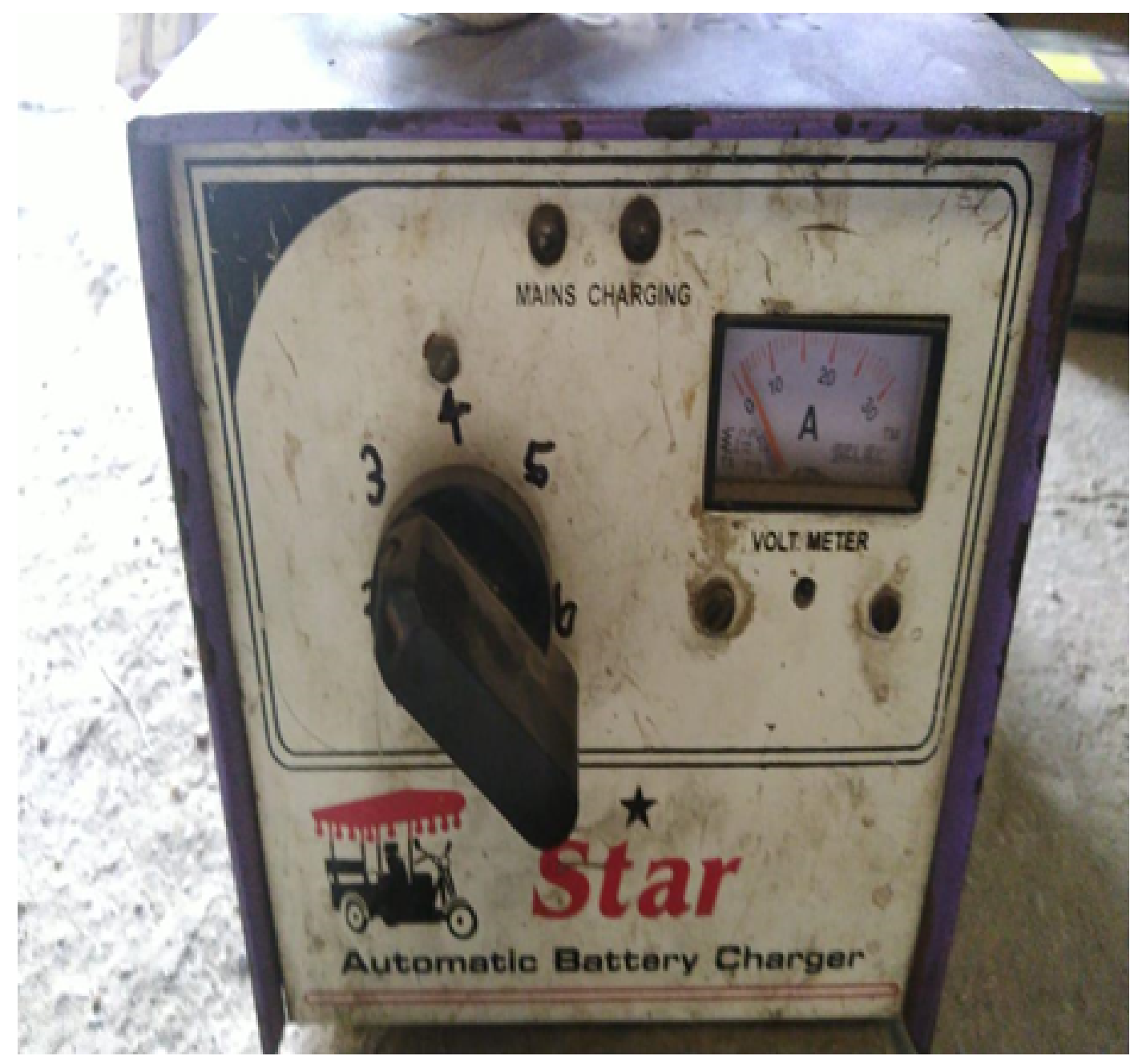

Fig 3. Conventional transformer-based chargers 


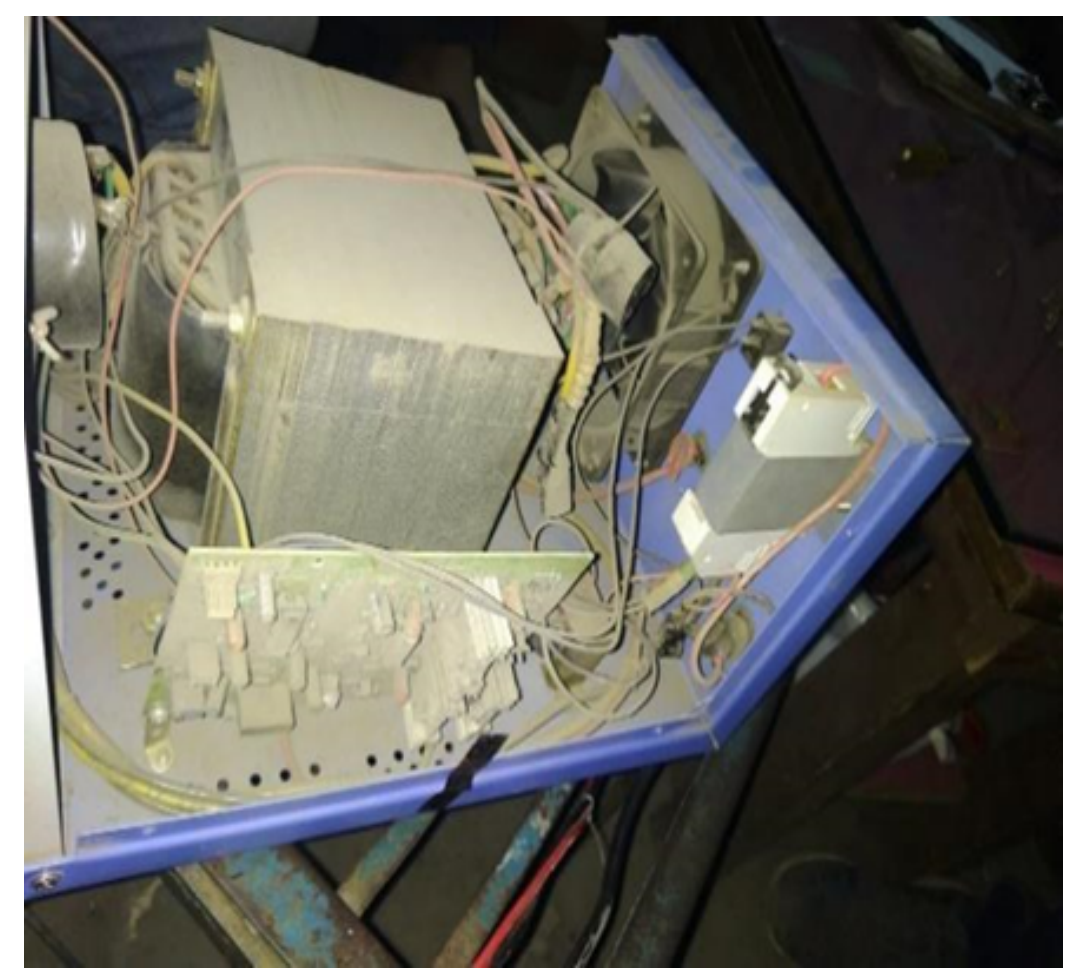

Fig 4. Interior assembly of transformer-based chargers

The e-rickshaws cannot be declared as a zero-emission mode as the energy that is required to charge the battery is supplied from thermal power plants. Thus, there is an indirect $\mathrm{CO}_{2}$ emission in the charging of e-rickshaws. In India, the coal-fired thermal power plants are known to emit $1.281 \mathrm{~kg}$ of CO2 per unit of electricity generated ${ }^{(9)}$. Since the transformer-based CC chargers don't operate at their rated values and the energy consumption being on the higher side, these leads to a greater $\mathrm{CO}_{2}$ emission. Table 4 shows the actual energy consumption of the charger.

Table 4. Data regarding the regular charger.

\begin{tabular}{ll}
\hline Parameter & Regular Charger \\
\hline Mode of Operation & Constant Current \\
Inner Circuit Design Base & Transformer Based \\
Standard Rating & $60 \mathrm{~V}, 12 \mathrm{Amps}$ \\
Charging Time*Assuming a 100 Ah battery according to minimum $^{*}$ & $8.5 \mathrm{Hours}$ \\
standards mentioned by ARAI / ICAT & \\
Energy Consumption (Rated) & 6 Unit \\
Energy Consumption (Actual) & 14 Unit \\
Electricity Cost / Charging Station & Rs. 1,00,000/- \\
Grid CO 2 Emission / Charging & $17.934 \mathrm{~kg}$ \\
Efficiency & $50-60 \%$ \\
Weight & $18 \mathrm{Kg}$ \\
Manufacturing \& Assembling & China (Manufacturing)India (Assembling) \\
\hline
\end{tabular}

\subsection{Overcharging}

The usual charging time for an e-rickshaw battery is $8-10$ hours at $0.1 \mathrm{C}$ rate. The EROs believe their batteries should be charged for at least 12 hours. However, the charging time varies from one ERO to another and this comes from the backdrop of two broad categories of ERO. 
1. The first one being an ERO who keeps his vehicle to charge for the entire night and continues on the following day. They charge their vehicles continuously for up to 14 hours. These operators believe more the charging time, longer the vehicle will run.

2. The second category of EROs put their rickshaws on charge at night, take it off early in the morning and come back for a top-up charge to their vehicles anytime during the day, typically during the lunch break. [ Figure 5] shows chart with different battery charging hours.

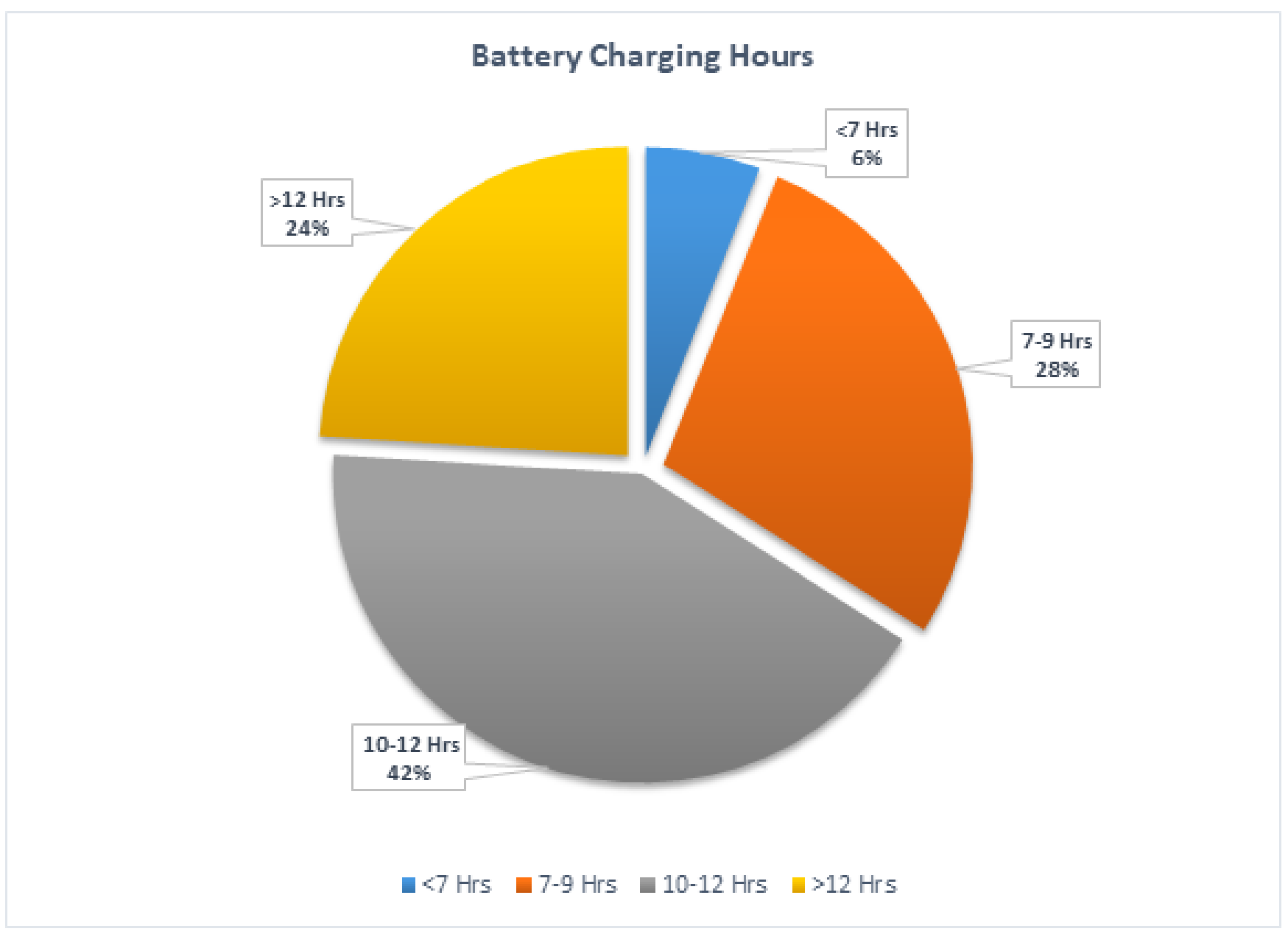

Fig 5. Share of different battery charging hours*

3. Much of the emphasis is given to Specific Gravity (SG) of the electrolyte. In an ideal condition, the SG should be $1.265 /$ cell $^{(10)}$. The SG which is although an indicator of the SoC, is misconstrued to be a measure of the battery performance. The EROs use local hydrometers for measuring the SG of the electrolyte. These hydrometers have incorrect scale measurements on them. To achieve the desired SG of the electrolyte, they tend to charge the battery to a point where the electrolyte starts to boil.

4. The EROs check the SoC of the battery by lifting the caps and checking for the boiling of electrolytes. If there is a sufficient boil in the electrolyte, they conclude that the battery is charged. This boiling is nothing but gassing. Beyond the gassing voltage, the electrolyte starts to overheat and there is a formation of hydrogen and oxygen gasses at the electrodes. This results in increased pressure inside the battery and the formed gasses find their way to escape out of the battery, this is called as gassing. Gassing leads to the boiling of electrolyte causing bubbling and loss of water content, also the decrease in the level of electrolyte is attributable to gassing which exposes the plates to the air, contributing to sulfation.

The costs of overcharging are borne by the CSO in terms of unnecessarily inflated electricity bills. The electricity bills vary from one CSO to another and depends on the capacity of holding e-rickshaws in that particular charging station. The practice of overcharging is costing the CSO exorbitant amounts and has to pay $75 \%$ more than necessary. 


\subsection{Precarious health conditions at the charging station}

Overcharging not only reduces the battery life but is also malicious for the air quality around the charging station. Overcharging leads to the breaking down of sulfuric acid $\left(\mathrm{H}_{2} \mathrm{SO}_{4}\right)$ into sulfur and hydrogen sulfide $\left(\mathrm{H}_{2} \mathrm{~S}\right)^{(11)}$. Every charging station near the study area smelled strongly of rotten egg during early morning which indicated a high concentration of hydrogen sulfide $\left(\mathrm{H}_{2} \mathrm{~S}\right)$. This hydrogen sulfide is directly inhaled by the caretaker of the charging station who sleeps in the vicinity of the e-rickshaws for the entire night with all doors closed and almost no ventilation measures. The caretaker is putting his life in jeopardy by being there all night and inhaling the toxic fumes. $\mathrm{H}_{2} \mathrm{~S}$ inhaled for a sustained period poses several health risks such as frostbite, respiratory tract problems, pulmonary edema and may also lead to death.

\subsection{Deep Discharge}

Every rickshaw has an onboard display which consists of an odometer as well as a battery SoC indicator. While on a trip, the ERO knows through this indicator that the battery is on the brink of complete discharge but due to monetary concerns, he prefers exhausting the battery putting jerks to draw currents beyond the permissible limits till he completes the current trip. These jerks drain the battery completely and sometimes the ERO is forced to pull his rickshaw manually or with the aid of a fellow ERO up to the charging station. This is nothing but Deep Discharging of the battery. Deep discharge is a state where electric potential energy is withdrawn below the cut off voltage. For instance, the normal operating range for a $12 \mathrm{~V}$ lead-acid battery lies between $10.5 \mathrm{~V}$ to $13.5 \mathrm{~V}$, former being the cut off voltage. Energy withdrawn below this point will lead to deep discharging of the battery.

The practice of deep discharging leads to sulfation. Sulfation is a phenomenon that occurs in a lead-acid battery when the electrolyte breaks down and sulfur ions loose free. The sulfur ion crystals then get attached to the electrodes, hence forming lead sulfate crystals. This coating of electrodes is ordinary during the discharge cycle. At around 10.5 volts, the plates are entirely covered with lead sulfate which can be converted back into lead and sulfuric acid only if immediately connected to a charger. Deep discharge also causes loss of capacity ${ }^{(12)}$. But e-rickshaws aren't put to charge immediately and also the charging cycles are non-uniform. If a lead-acid battery is not immediately put to charge, the lead sulfate will begin to form hard crystals, which cannot be reconverted by the regular chargers employed there and the battery is then permanently damaged.

Charging and discharging are a result of a reversible chemical reaction occurring inside the battery. Continuous discharging below the cut off voltage causes sulfation and makes these reactions irreversible, increasing the internal resistance of the battery and simultaneously increasing the charging time. The average life cycle of a battery is in inverse proportion with the depth of discharge i.e. lower the depth of discharge higher the life cycles and vice versa. These jerks are hence energy drawn from the battery below the cut off voltage and is one of the major reasons why batteries die soon in an e-rickshaw ${ }^{(13)}$.

\section{Alternate charging techniques}

Almost all the EROs put their vehicles for a top-up charge during day time, for 2-3 hours. The current chargers partially charge the batteries in this time window and hence the ERO returns back early in the evening. In this case, the battery remains deprived of a full charge and continuously depriving the battery of full charge contributes to sulfation. Thus, to resolve this problem, a fast charging algorithm can be implemented which could charge the battery completely within that time bracket enabling the ERO to work for an extended period, returning directly at night. This way the ERO can earn more. Significant research work has shown that the fast charging of lead-acid batteries has no deleterious effects on the battery life ${ }^{(14)}$. Contrary to prior beliefs, a fast-charging methodology that marginalizes the effects of oxygen cycle and charges quicker can result in an increased battery life cycles ${ }^{(15)}$. This section reviews the modern charging techniques that can be implemented with fast charging feature.

\subsection{Constant current-constant voltage (CC-CV) charging technique}

This method is the combination of the traditional CC and CV methods. CC-CV algorithm operates in 3 stages. In first, the charger operates in Constant Current (CC) mode. Approximately $80 \%$ of the charge is returned to the battery within two hours. Once the voltage reaches the set level, the current level starts to fall keeping the voltage constant, this is the Constant Voltage (CV) mode. The third stage is the Float mode where a constant voltage of $2.25 \mathrm{~V}$ per cell is maintained to fill the remaining charge. Full SoC is reached when the current reaches approximately $5 \%$ of the rated Ah capacity [i.e. 5-5.5A for a $100 \mathrm{Ah}$ erickshaw battery]. [ Figure 6] shows a controller circuit for a CC-CV algorithm-based charger.

The advantage of using CC-CV algorithm in the e-rickshaw will be that the charging cycle will get uniform and disciplined. And because of uniform charging cycles, the battery life will automatically increase. 


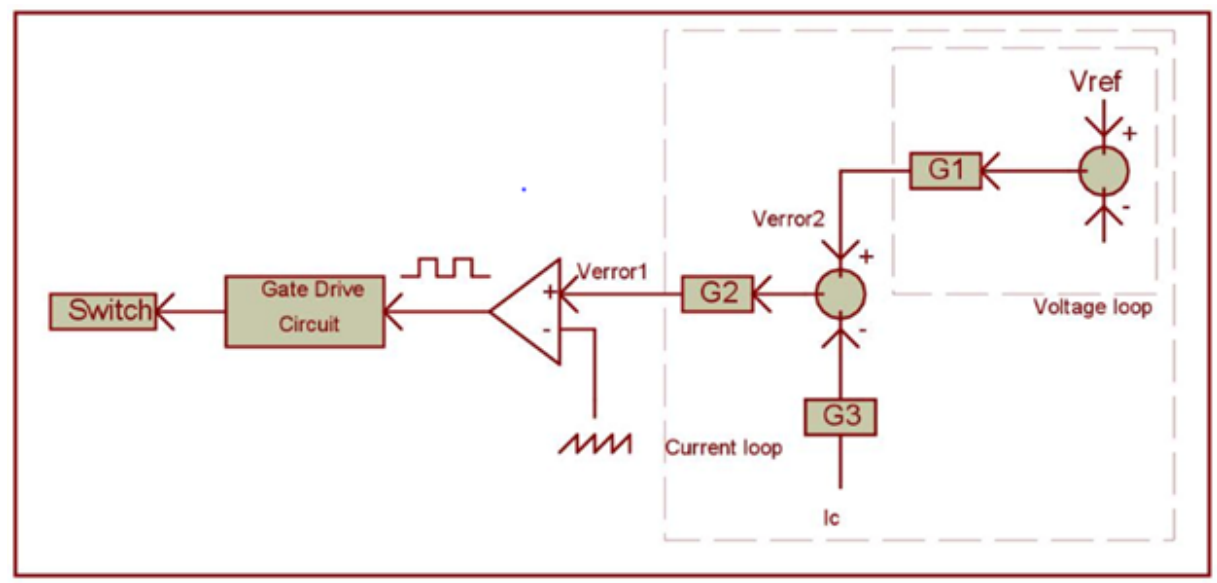

Fig 6. Controller circuit for a CC-CV algorithm charger.

\subsection{Pulse current charging technique}

Pulse charging technique involves providing high pulse current to the battery instantaneously. Increasing the charging speed of the charger requires boosting the charging current magnitude. And boosting the current magnitude attracts the polarization phenomenon, which impedes the energy being stored. To reduce the charging time, it becomes necessary to nullify the effect of polarization. A copious literature is available which discusses how the pulse charging technique makes use of discharging the battery instantaneously during the charging, that helps abstain polarization. Pulse chargers operate in three stages, at first a periodical pulse is provided to the battery. The second stage follows a deep discharge imposed by the charger for a short instant of time. In the discharge phase, the ions on the two electrodes move against the direction of the charging current, this results in the reduction of the accumulated ions on the electrodes and in all the polarization. In addition to this, the movement of ions against the conventional direction of current leads to a part of heat energy generated from ohm polarization transferred to the load, which circumvents the battery from overheating. The discharge mode is realized by giving a negative pulse through the charger module which also significantly ameliorates the polarization concentration by stirring the electrolyte. The final stage is the waiting instant ${ }^{(16)}$. [ Figure 7] shows a functional waveform of the pulse current based chargers.

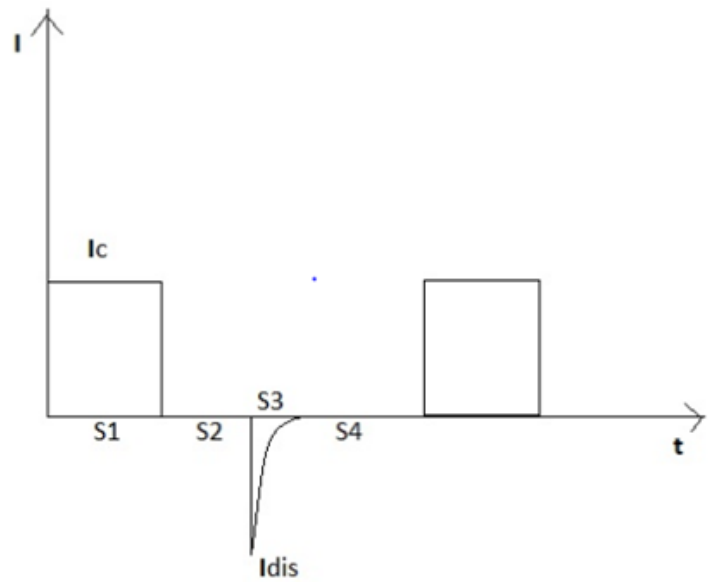

Fig 7. Graph showing functional waveform of the pulse current based chargers. 
It is recorded that the charging process with pulsed current charging technique is nearly $\sim 15$ to $\sim 30 \%$ efficient than with other charging techniques particularly the invariant-current schedule ${ }^{(17)}$. Also, to mention that the high pulses given to charge the battery causes no degradation of the active material on the electrodes. Rather, the high pulsed current technique enables oxidation at a faster pace ${ }^{(18)}$. When it comes to fast charging, this technique is able to reduce the charging time by a significant margin, i.e. $\sim 12 \mathrm{~h}$ to $\sim 1.2 \mathrm{~h}$. Also, the technique is known to augment the battery cycle life performance as well as leads to recovery of the battery capacity ${ }^{(19)}$.

The pulse based fast chargers involve power electronic circuits that include capacitors, IGBTs, switches and diodes as shown in [ Figure 8]. The pulse based fast charger works in forward and reverse bias. In the forward bias, it functions in the buck mode, whereas, in the reverse bias functions in the boost mode.

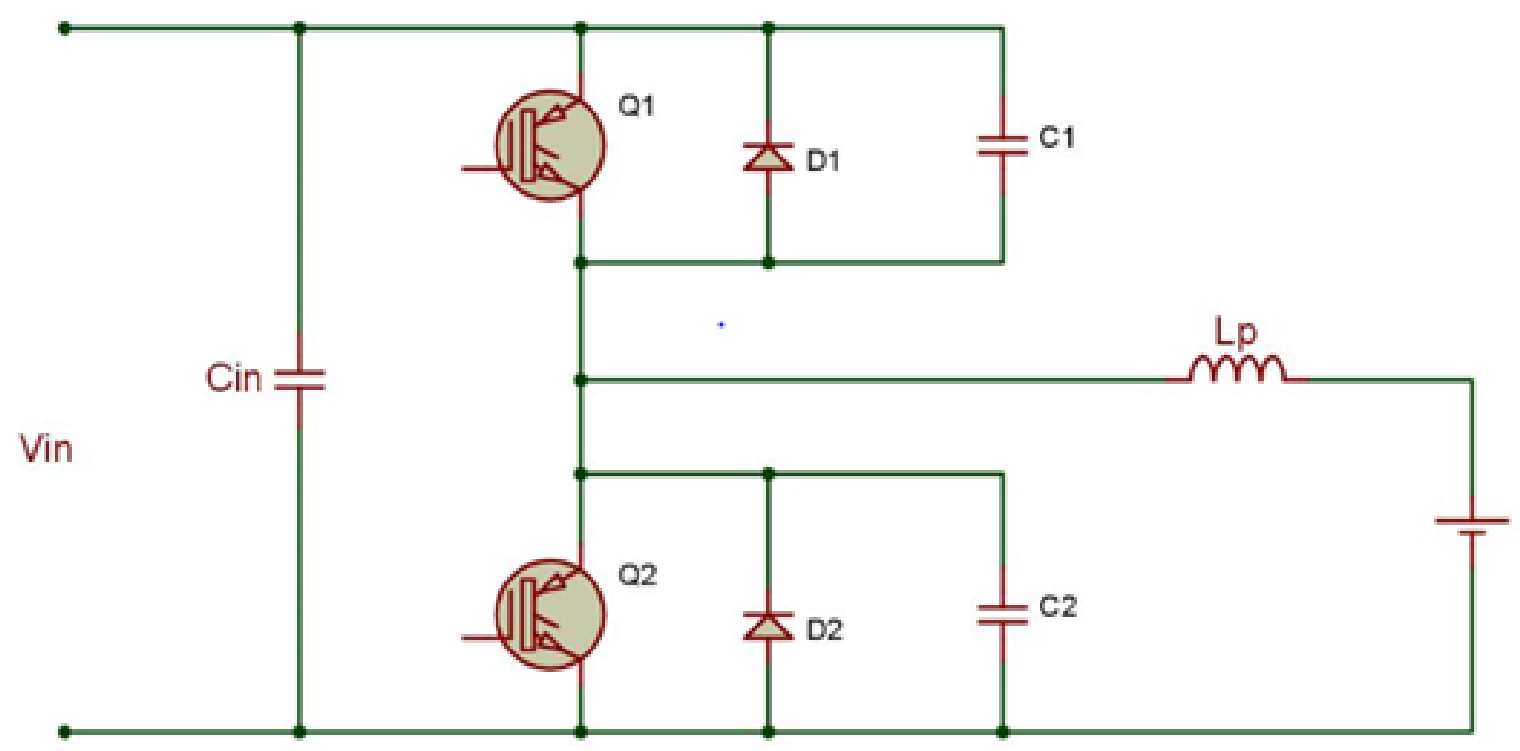

Fig 8. Circuit of a pulse current based fast charger.

\subsection{Superimposed pulse frequency charging technique}

As discussed above, sulfation directly contributes in reducing the e-rickshaw battery life. So totackle the sulfation, the other normally used chargers particularly the CC-CV chargers can have a modified circuit which induces the superimposed pulse frequency generated by a DC/DC converter. The operation of this DC/DC converter takes in such a manner that the pulse generated by it in turn generates a mechanical resonance at the sulphation zones. The mechanical resonance causes shocks and vibrations at the sulphated plates. This vibration causes elimination of the pores attached to the sulphated plate. The charger for such a technique requires 2 separate converter units. One unit acts as a main unit which functions as the main charger and controls the current level and dc voltage. The other unit acts as an auxiliary converter whose output voltage is added as a superimposed waveform on the output of the main charger. The superimposed pulse frequency-based chargers are known to increase the battery lifetime and charge capacity respectively. [ Figure 9] shows a two-converter topology of the superimposed pulse frequency based fast charger. 


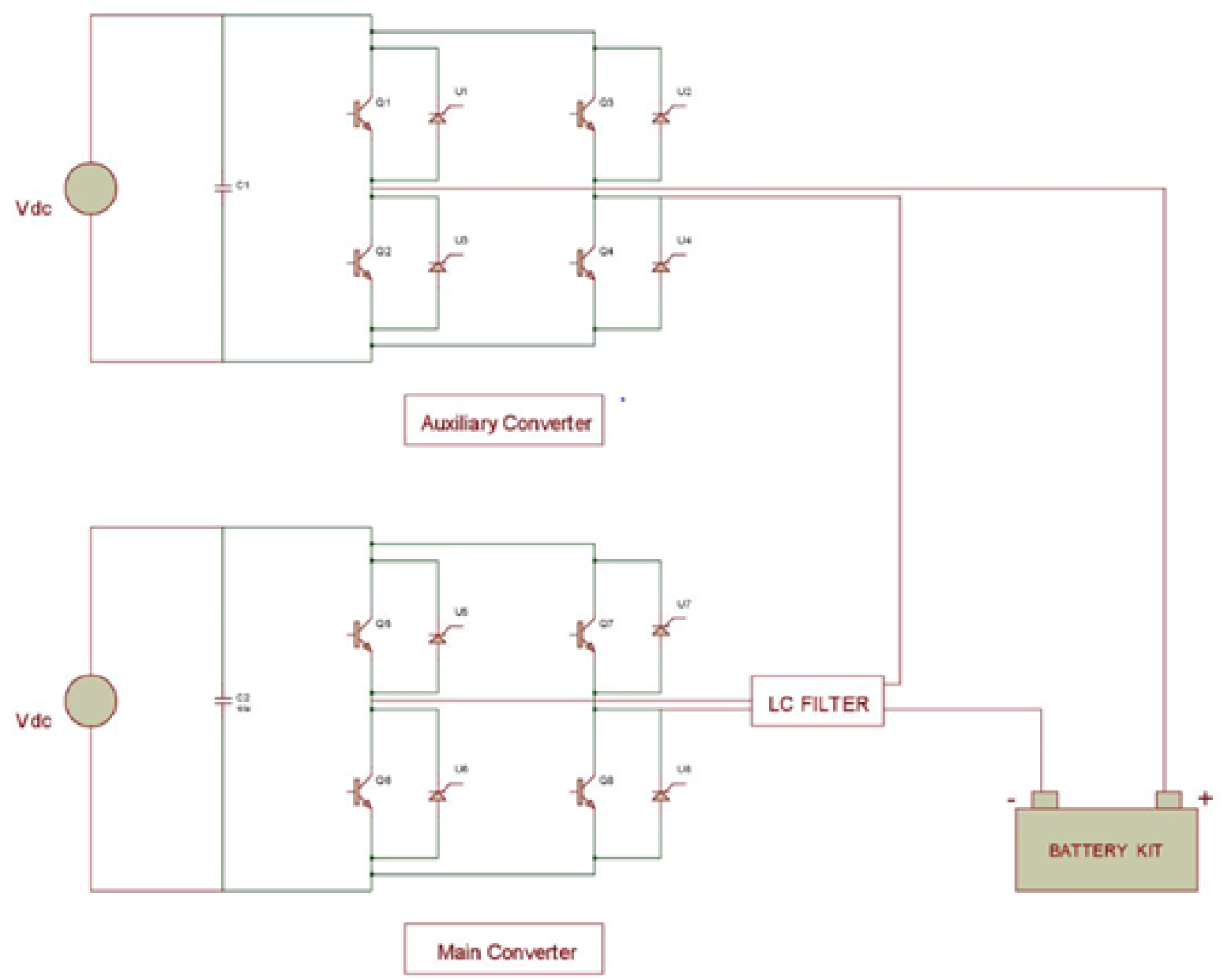

Fig 9. The two-converter topology of the superimposed pulse frequency based fast charger

Experiments conducted to test SPF based chargers suggest that the specific gravity magnitude is directly proportional to the applied frequency ${ }^{(20)}$. The frequency can be varied between $1 \mathrm{KHz}$ to nearly $3 \mathrm{MHz}$. The specific gravity level which is indicative of the charge was maximum with the highest frequency applied via the charger. Although the specific gravity difference between the charge level reached at $5 \mathrm{KHz}$ and that with $3 \mathrm{MHz}$ was minimal. The graph below shows the same.

In their field test, fourteen batteries with sulfation were put to test for 72 hours. Twelve of them showed significant results of desulfation ${ }^{(21)}$. The rest two batteries which didn't show any signs had their electrode plates degraded severely. The plates degraded were a result of overcharging and deep discharging. The field test suggests that with SPF, batteries can be revived and an overall $\sim 86 \%$ success rate is observed in reviving the sulphated batteries. The results show that SPF based fast chargers can be implemented in the e-rickshaw technology and hold the capacity to substantially increase the e-rickshaw battery life by nearly an year. Also, a SPF based high current charger is more efficient and bolsters the performance of the battery. It is easier to design and build and is economical too when tuned at lower frequencies.

\subsection{Intermittent charging technique}

The multistage CC-CV chargers poses one major problem with the float charging stage. The float charging achieved within constant voltage mode allows the battery to suck the maximum current. An optimum float voltage should be chosen between 2.25 2.30 V/cell. This optimum float voltage allows a float mode current to compensate for the self-discharge of the battery. This current also suffices for the positive grid corrosion requirement as well as the oxygen recombination processes. In the 
multi-stage CC-CV chargers, this float voltage is present even after the battery gets full charged. Due to this, a high float current magnitude gets into play and contributes in overcharging with effusion of hydrogen sulphide $\left(\mathrm{H}_{2} \mathrm{~S}\right)$ and grid corrosion ${ }^{(20)}$. The grid corrosion (positive) is another factor which contributes to the shortening of battery lifetime.

Intermittent charging technique (ICT) is the technique which focuses on eliminating the problem of grid corrosion and increasing the battery lifetime. ICT is renowned to abstain from overcharging which is the main cause of battery failure. In ICT, the charger charges the battery for some period of time, then it is allowed to discharge up to a threshold value, beyond which recharging is again provided to the battery. As the process involves sporadic charging, it is called as intermittent charging. The entire process of the ICT can be elucidated in the following step diagram. After the battery is charged to full, the charger is disconnected keeping the battery in an open circuit condition. The voltage in that condition is monitored. When the monitored voltage comes down to a threshold value which is mostly a fixed value equal to $\sim 97 \%$ of the SoC, the charger is again connected across and battery is charged up to full capacity ${ }^{(22)}$.

According to the literature, the ICT based chargers can be implemented with the constant current charging for the upper and lower voltage thresholds ${ }^{(23-25)}$. One drawback is that constant current charging doesn't guarantee a full charge return which may lead to the battery being not charged causing sulfation and reduction in the active surface area of the electrodes ${ }^{(22)}$. However, the current magnitude within this mode can be safely increased beyond C/3 ratings. To bolster the claim that ICT increases the battery life, an experiment was made where a comparison was made between the ICT and the constant voltage technique. The [ Figure 10] below displays the result which proves that the on a longer run ICT technique substantially extends the battery life and can be implemented within the e-rickshaw ecosystem.

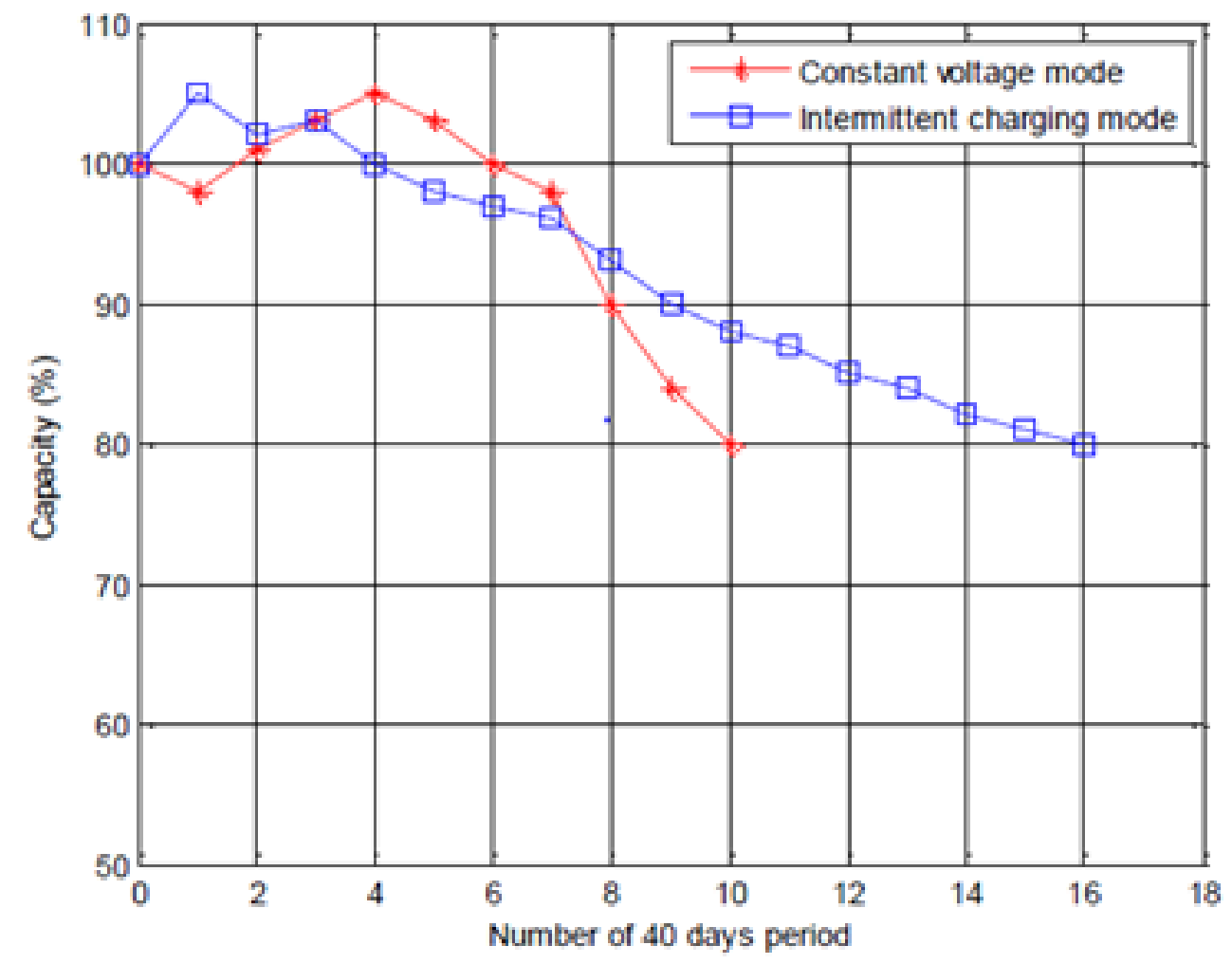

Fig 10. Comparison between ICT and CV algorithms*.

HorkosYammine and N. Karami3 International Conference on Technological Advances in Electrical, Electronics and Computer Engineering (TAEECE), Beirut. 2015; 27-32. DOI: 10.1109/TAEECE.2015.7113595. 


\subsection{Interrupted charge control technique}

As the issue of undercharge poses problem for the battery with the ICT, some modifications are made to the ICT based chargers such that the battery is full charged and the undercharge conditions are eliminated. The charging technique of interrupted charge control technique (ICCT) based chargers is similar to ICT, i.e. commencement with constant current mode up to an upper level voltage threshold. This is followed by a self-discharge phase until the voltage reaches a lower threshold value. However, beyond this mode in ICCT, a pulse current mode is applied until the end of charge to ensure that the battery is full charged.

The current magnitudes can be chosen according to the requirement which enables efficient fast charging feature with ICCT chargers. However, it is to be made sure that the threshold parameters are selected diligently, these parameters include the battery voltage, current, and temperature. [ Figure 11] below shows the block diagram of the ICCT based charger.

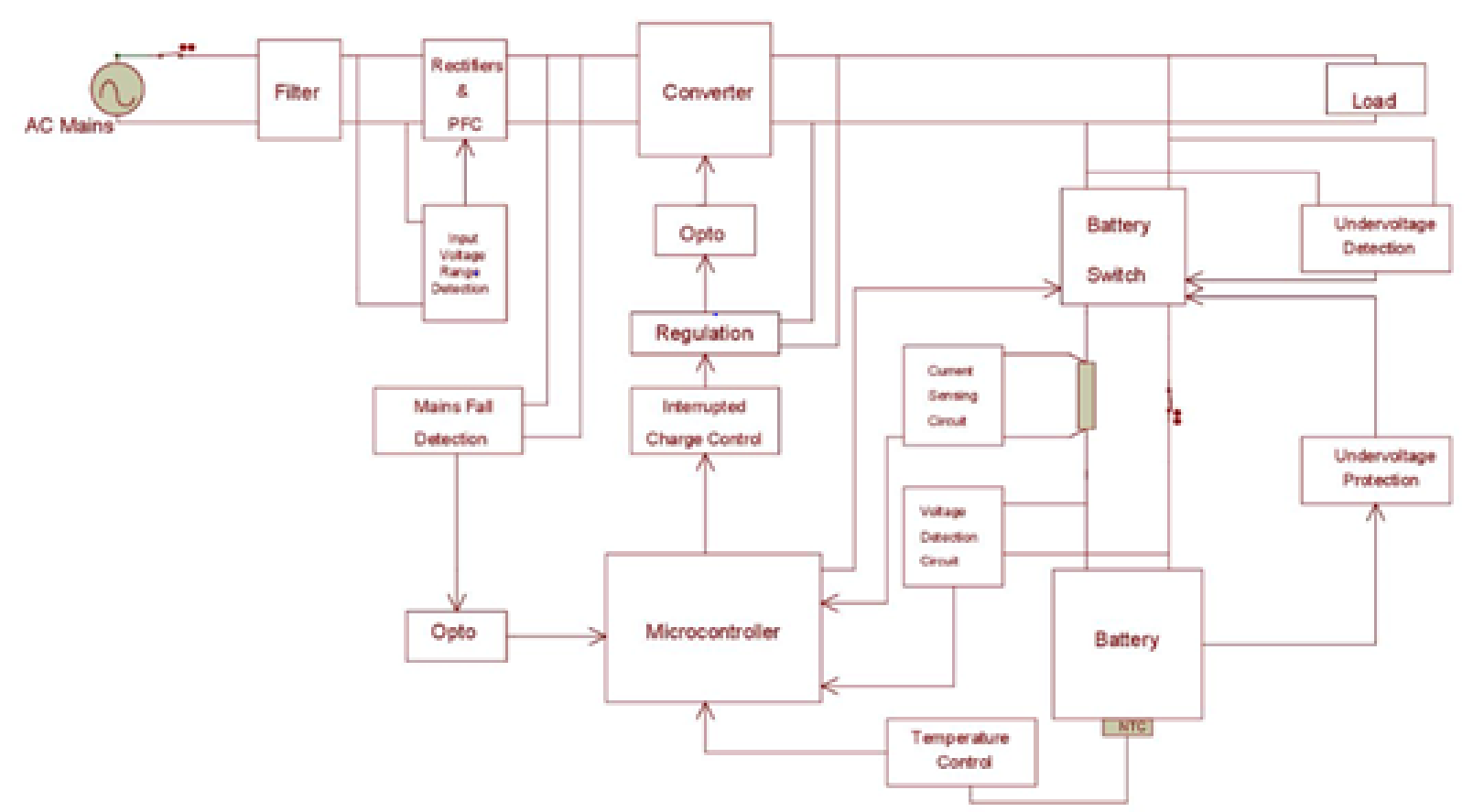

Fig 11. Block diagram of an ICCT based fast charger.

The battery is connected across the DC-DC converter via a battery switch which is nothing but a low resistance switch. The DC-DC converter acts as pulse width-modulation (PWM) switching regulator. The current mode control is used for the implementation of the fly-back converter as a regulator. This current mode control has an overcurrent protection and also aids as a current pulse current limiter. The PIC microcontroller plays a vital role in the circuit of the ICCT based charger, accommodating itself to the intermittent charging technique which generates the voltage and current values which act as a set point for the regulation circuit. The temperature values of the battery are also a function of the PIC (excessive temperature recordings lead to termination of the charging). The battery voltage and the charging current are monitored continuously by the voltage and current detection circuits, and are fed back to the PIC ${ }^{(22)}$.

The ICCT based chargers combine both ICT and pulsed charging technique. This technique is particularly advantageous as it brings down the grid corrosion to a minimal value and also the scope of overcharging or the battery not getting a full charge is completely eliminated. Combining such features together with the fast charging feature would suffice all the needs which the e-rickshaw technology in the study area are in a dire need of.

\section{Hybrid energy systems}

A hybrid energy system is a combination of an ultracapacitor connected in parallel with the battery (lead-acid or lithiumion). The lead-acid batteries employed in e-rickshaws have a high energy density than the power density, and hence during the 
peak loads, there is a lot of stress on the battery alone which weakens it's operating life cycles. In a hybrid energy system, this stress is taken over by an ultracapacitor which exudes high power density to compensate for the peak loads. Hybrid energy systems in electric-vehicles are known for increasing the efficacy of the system and are also known for increasing the battery life significantly ${ }^{(26)}$. In a test ride for checking the range of the battery, it was observed during an uphill climb, that a lot of stress is put on the battery. If the battery isn't charged, the e-rickshaw won't be able to climb the uphill in any condition. This is the same reason why EROs do not prefer riding through a flyover which would otherwise reduce the journey time by almost half. Employing a hybrid energy system would increase the range of the vehicle and also increase the e-rickshaw battery life. The hybrid energy systems have their own topologies. This includes coupling the two energy sources with a common DC link, connect them with a single bidirectional DC-DC converter at any of the two sources [ Figure 12], or using two different DC-DC converters for each ${ }^{(27)}$. However, in this case, hybrid system coupled via a direct DC link is more apt considering the economics. Thus, considering strengthening the e-rickshaw battery life, a hybrid energy system could be employed. This would also help EROs to take flyovers which would help distribute the traffic density evenly.

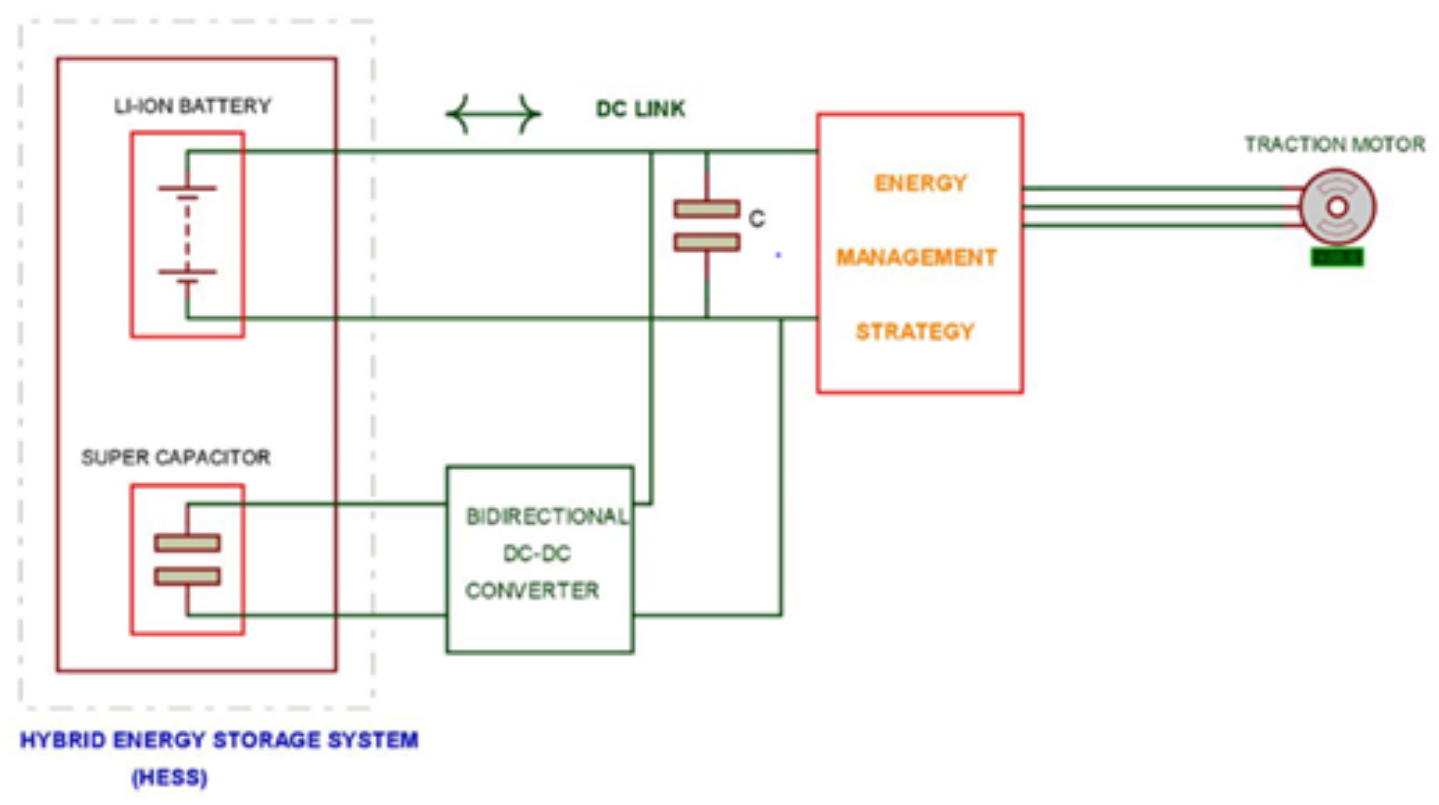

Fig 12. Block diagram of hybrid energy storage system

*Source- S.Tirpude, Bharadwaj Dubey Holmukhe International Journal of Emerging Trends in Engineering Research10.30534/ijeter/2020/12872020

\section{Observation}

While all the aforementioned techniques augment the battery life and are suitable to be applied in the e-rickshaw ecosystem, these techniques certainly have their limitations. The CC-CV method is known to emit comparatively more gas during the final stages which impedes the battery functioning. The pulse current based chargers have low comparative efficiency (in terms of power electronic devices) against the other methods. The superimposed pulse frequency-based chargers have just recently begun to come into the picture and are higher on the cost scale and also a bit complicated to design. The ICT and the ICCT are much modern compared to the others. The only issue with ICT based chargers is the undercharge condition. The ICCT certainly eliminates the undercharge issue with ICT chargers and as of now seems to be free from major defects. However, the absence of a major defect is completely because this algorithm is new and research is on-going ${ }^{(28)}$.

The most important criteria for the ERO is the affordability of the charger, because at last it is the ERO who has to purchase the charger. The pulse-based, ICT and the ICCT-based chargers employ heavy power electronics and complex designs which 
adds up to the cost. Thus, seeing the cost benefit, CC-CV based fast charger is more suited for the e-rickshaw technology.

The CC-CV technique will also reduce the unit consumption at the charging stations, reducing the electricity tariffs. A fastcharging algorithm added to these chargers will further increase the life cycles of the battery thus benefitting the EROs by enabling them to earn an extended margin of time pacifying their financial burden.

Hybrid energy system consisting of the $48 \mathrm{~V}$ lead-acid battery connected in parallel with ultracapacitor bank could be an additional technical step that can be taken to ameliorate the range anxiety of the ERO. Hybrid energy systems are known for sufficing both the need for power density as well as energy density which would make e-rickshaw technology much efficient. Reduction in the stresses on the battery during peak load (driving on an uphill) will make sure healthy operation which will help augment the battery life of e-rickshaw.

Thus, upgrading and imbibing to the proposed systems will increase the profitability of the ERO and the CSO to a great extent.

\section{Conclusion and Recommendations}

The study sheds light on the practices that are being carried out on the field and how the current charging algorithm is depriving the battery of its natural life span. The CC based charging algorithms together with the practices cause the battery's premature failure and also is a detriment to the environment of the charging station.

The chargers overcharge the battery which leads to gassing and subsequently sulfation. The overcharging costs the CSO tremendous amounts for his electricity bills. Also, the gassing exposes $\mathrm{H}_{2} \mathrm{~S}$ in the surroundings and continuous inhalation of $\mathrm{H}_{2} \mathrm{~S}$ is detrimental to the health of the caretaker and CSO. Hence, it is concluded that there is a need of upgrading the charging techniques used in the battery chargers. The CC-CV algorithm was found to be the most suitable of all the modern techniques, owing to its affordability. In addition to this, a hybrid energy system comprising of an ultra-capacitor bank connected in parallel with the battery can be used to further enhance the e-rickshaw battery life.

\section{References}

1) Juyal S, Saxena A, Sharma S, Srivastava A, Jain R, Ritolia R, et al. Transforming India's Mobility: A perspective. 2018. Available from: https://niti.gov.in/ writereaddata/files/document_publication/BCG.pdf.

2) India GHG Program, IGHGP. India Specific Road Transport Emission Factors. India GHG Program. 2015. Available from: https://shaktifoundation.in/ wp-content/uploads/2017/06/WRI-2015-India-Specific-Road-Transport-Emission-Factors.pdf.

3) ] Ministry of Road Transport, MORT. An Overview: Road Network of India. Ministry of Road Transport, Government of India. 2010.

4) Unorganized Players with Cost Edge Lead the e-Rickshaw Race. . Available from: https://economictimes.indiatimes.com/industry/auto/auto-news/ unorganised-players-with-cost-edge-lead-the-e-rickshaw-race/articleshow/71788181.cms?from $=\mathrm{mdr}$.

5) Harding S, Rojesh S. Battery Rickshaws in New Delhi and the Regulation Conundrum. Economic and political weekly. 2014;35:43-47. Available from: https://www.jstor.org/stable/24480494.

6) Market Potential in India, 2019 with Demand Projections till 2025 - Cab Aggregators Like Ola \& Others are Moving to the E-Rickshaw. . Available from: https://www.businesswire.com/news/home/20191104005342/en/E-Rickshaw-Market-Potential-India-2019-Demand-Projections. Dateaccessed:09/05/2020.

7) Prescient \& Strategic, P.S. India Electric Rickshaw Battery Market to Generate Revenue Worth $\$ 722.3$ Million by 2024. Prescient \& Strategic (P\&S) Intelligence Private limited 2020. . Available from: https://www.psmarketresearch.com/press-release/india-electric-rickshaw-battery-market\#.

8) Shah S. The Issue of Lead-Acid Batteries in India. 2019. Available from: http://www.greenworldinvestor.com/2019/09/12/the-issue-of-lead-acidbatteries-in-india/.

9) Jash T. Renewable energy and environment. Geographical Review of India. 2007;69(1):20-24.

10) Megateli RM, Idir G, Arab AH. Study of the variation of the specific gravity of the electrolyte during charge/discharge cycling of a lead acid battery. $3 r d$ International Conference on Control, Engineering \& Information Technology (CEIT). 2015. Available from: https://doi.org/10.1109/CEIT.2015.7232980.

11) Tenno A, Tenno R, Suntio T. Evaluation of VRLA battery under overcharging: model for battery testing. Journal of Power Sources. 2002;111(1):65-82. Available from: https://dx.doi.org/10.1016/s0378-7753(02)00276-8.

12) Ruetschi P. Aging mechanisms and service life of lead-acid batteries. Journal of Power Sources. 2004;127(1-2):33-44. Available from: https://dx.doi.org/ 10.1016/j.jpowsour.2003.09.052.

13) Merrouche W, Achaibou N, Bouzidi B, Kasser M, Trari M. Lead-acid Battery Degradation Mechanisms in Photovoltaic Systems PVS. In: and others, editor. The 3rd International Workshop on Integration of Solar Power into Power Systems SIW2013. 2013. Available from: https://www.researchgate.net/profile/Walid_Merrouche/publication/258374566_Lead-acid_Battery_Degradation_Mechanisms_in_Photovoltaic_ Systems_PVS/links/02e7e528319ff78c67000000.pdf.

14) Dhameja S. Electric Vehicle Battery Systems. 1st ed. Boston, USA.. Newnes. 2001.

15) Rand AJD, Moseley PT, Garche J, Park CD. Valve-regulated Lead-Acid Batteries. 1st ed. Amsterdam, the Netherlands. Elsevier Science. 2004.

16) Qian P, Guo M. Design of Pulse Charger for Lead-Acid Battery. In: Hu W, et al., editors. Electronics and Signal Processing, Lecture Notes in Electrical Engineering;vol. 97. Springer. 2011;p. 897-901. Available from: https://doi.org/10.1007/978-3-642-21697-8_115.

17) Lam LT, Ozgun H, Cranswick LMD, Rand DAJ. Pulsed-current formation of tetrabasic lead sulfate in cured lead/acid battery plates. Journal of Power Sources. 1993;42(1-2):55-70. Available from: https://dx.doi.org/10.1016/0378-7753(93)80137-e.

18) Hua CC, Lin MY. A study of charging control of lead-acid battery for electric vehicles. In: Proceedings of the 2000 IEEE International Symposium on Industrial Electronics (Cat. No.00TH8543);vol. 1. 2000;p. 135-140. Available from: https://doi.oorg/10.1109/ISIE.2000.930500. 
19) Lam LT, Ozgun H, Lim OV, Hamilton JA, Vu LH, Vella DG, et al. Pulsed-current charging of lead/acid batteries - a possible means for overcoming premature capacity loss? Journal of Power Sources. 1995;53(2):215-228. Available from: https://dx.doi.org/10.1016/0378-7753(94)01988-8.

20) Rand DAJ, Boden DP, Lakshmi CS, Nelson RF, Prengaman RD. Manufacturing and operational issues with lead-acid batteries. Journal of Power Sources. 2002;107(2):280-300. Available from: https://dx.doi.org/10.1016/s0378-7753(01)01083-7.

21) Khanal RR, Kayastha RK. Effect of Pulse charging in lead acid batteries used in electric vehicles in Nepal. Proceedings of IOE Graduate Conference. 2017. Available from: http://conference.ioe.edu.np/publications/ioegc2017/IOEGC-2017-23.pdf.

22) Bhatt M, Hurley WG, Wolfle WH. A New Approach to Intermittent Charging of Valve-Regulated Lead-Acid Batteries in Standby Applications. IEEE Transactions on Industrial Electronics. 2005;52(5):1337-1342. Available from: https://dx.doi.org/10.1109/tie.2005.855665.

23) Muneret X, Coux M, Lenain P. Analysis of the partial charge reactions within a standby VRLA battery leading to an understanding of intermittent charging techniques. In: INTELEC, 22 International Telecommunications Energy Conference (Cat. No.00CH37131). 2000;p. 293-298. Available from: https://doi.org/10.1109/INTLEC.2000.884264.

24) Waltari P, Suntio T, Tenno A, Tenno R. The effects of intermittent charging on VRLA battery life expectancy in telecom applications. In: 24th Annual International Telecommunications Energy Conference. 2002;p. 121-127. Available from: https://doi.org/10.1109/INTLEC.2002.1048644.

25) Rossinot E, Lefrou C, Dalard F, Cun JP. Batteries in standby applications: comparison of alternate mode versus floating. Journal of Power Sources. 2001;101(1):27-34. Available from: https://dx.doi.org/10.1016/s0378-7753(01)00483-9.

26) Horkos PG, Yammine E, Karami N. Review on different charging techniques of lead-acid batteries. In: and others, editor. 3rd International Conference on Technological Advances in Electrical, Electronics and Computer Engineering (TAEECE). 2015;p. 27-32. Available from: https://doi.org/10.1109/ TAEECE.2015.7113595.

27) Barcellona S, Piegari L, Villa A. Passive hybrid energy storage system for electric vehicles at very low temperatures. Journal of Energy Storage. $2019 ; 25$. Available from: https://dx.doi.org/10.1016/j.est.2019.100833.

28) Horkos PG, Yammine E, Karami N. Review on different charging techniques of lead-acid batteries. In: and others, editor. 3rd International Conference on Technological Advances in Electrical, Electronics and Computer Engineering (TAEECE). 2015;p. 27-32. Available from: https://doi.org/10.1109/ TAEECE.2015.7113595. 